\title{
RICARDO E. LATCHAM, UN CIENTÍFICO SOCIAL. DESDE LAS OBSERVACIONES ETNOGRÁFICAS DE LA SOCIEDAD HASTA LA ARQUEOLOGÍA DE LAS CULTURAS ORIGINARIAS CHILENAS ${ }^{1}$
}

Ricardo E. Latcham, a social scientist. From ethnographic observations of society to the archaeology of Chile's original cultures

José Antonio González Pizarro*

\section{Resumen}

Se analiza la presencia intelectual de Ricardo Eduardo Latcham, ingeniero inglés, que llegado a Chile dio un mayor impulso al estudio tanto de la prehistoria latinoamericana como de la arqueología chilena, en los ámbitos del hábitat araucano y de las culturas del norte, en especial la atacameña. En este sentido, sus investigaciones prosiguieron a las de Uhle y posibilitaron integrar a los pueblos originarios del norte chileno al panorama de la prehistoria nacional. Latcham se adentró en registrar las conductas de la sociedad chilena, tanto culta como popular, de fines del siglo XIX, legando agudas anotaciones etnográficas conjuntamente con una labor de tenaz divulgador de los progresos de la antropología europea, convirtiéndose en un corresponsal de las revistas británicas de la disciplina. Sus obras mayores las pudo difundir en el marco de sus actividades en el Museo de Historia Natural y en la Universidad de Chile.

Palabras clave: Ricardo E.Latcham, Arqueología, Antropología, Araucana, Atacameña

Abstract

The intellectual presence of Ricardo E. Latcham, an English engineer whose arrival in Chile gave greater impulse to the study of Latin American pre-history and Chilean archaeology regarding araucano habitat and northern cultures, particularly the atacameno culture, is analyzed. His studies continued those of Uhle's and made it possible to integrate the originary peoples of northern Chile to the panorama of the national pre-history. Latcham recorded the behaviors of both educated and popular Chilean society at the end of the $19^{\text {th }}$ century, producing deep ethnographic records. He also conducted an enthusiastic dissemination of the progress made by European anthropology, becoming a correspondent of the British journals of this discipline. He disseminated his major works while working for the Museum of Natural History and the University of Chile.

Key words: Ricardo Ricardo E. Latcham, Archaeology, Anthropology, Araucana, Atacameña

\footnotetext{
${ }^{1}$ El trabajo se enmarca en la ejecución del proyecto Fondecyt $\mathrm{N}^{\circ} 1100074$ y forma parte del proyecto NS 100046 de la Iniciativa Científica Milenio del Ministerio de Economía, Fomento y Turismo, Chile.
} 


\section{LA LLEGADA DE RICARDO E. LATCHAM A CHILE Y PRIMERAS IMPRESIONES}

Ricardo Eduardo Latcham Cartwright, nació el Bristol, Inglaterra, el 5 de marzo de 1869. Sus padres fueron Tomás Latcham, de profesión contador en los servicios municipales, y Victoria Cartwright. Un hogar establecido al mejor estilo victoriano que imperaba entonces. Sus estudios los cursó en el Board School, en 1875-1879 y los concretó en el Queen Elizabeth's Hospital, en 1884. Se tituló de ingeniero civil en el Polytechnical Institute de Londres, en 1888. Su carácter, anota Feliú Cruz (1969), fue inclinado a los deportes, especialmente al fútbol y a las excursiones, "era imaginativo y de sólido criterio en la apreciación de las cosas, especialmente para desmenuzar las ideas, resumirlas y presentarlas con novedad...simpático, cordial" (Feliú, 1969:6-8).

Una circunstancia le conduciría a Chile. Martin Drouilly había sido encomendado por el gobierno de Chile, para buscar personas competentes que afianzaren la colonización en la región de Bío-Bío y Cautín. Contactó a Latcham en el Polytechnical Institute y éste aceptó de inmediato. Era el año 1888. Consigna uno de sus biógrafos que el conocimiento de Chile provenía de las novelas de James Fenimore Cooper (Lothrop, 1945:603).

La denominada "Frontera" como se llamaban a estos territorios que el Estado había comenzado a penetrar desde 1862 y mediante la guerra había concluido su "Pacificación" en 1884, había desarticulado a la etnia mapuche, sea con la reducción de unos, la campesinización de otros y un resto viviendo la pobreza urbana (Pinto, 2003).

Chile hacia el año 1888, mostraba exiguas obras en el campo antropológico. Seis años antes José Toribio Medina había publicado Los aborígenes de Chile, que Latcham estimó el primero de su tipo y de vigencia en la década de 1920 (Latcham, 1924:307). El libro de Medina marcó una inflexión sobre la visión de la prehistoria en Chile, advirtiendo que el Arauco independiente podría desaparecer por esta "guerra de pacificación", pero siempre iba a subsistir su influencia, recuerdos y herencia en nuestros antepasados. A su vez, Diego Barros Arana se encontraba en pleno proceso de estudio y redacción de su monumental Historia General de Chile, cuyo primer volumen había aparecido en 1884, dejando establecida su tesis de la homogeneidad étnica de los indígenas chilenos - principalmente los mapuches - con lo cual era fácil de entender su impresión fría y distante, de la exhibición de algunos indígenas "salvajes"- de la Tierra del Fuego en Berlín, el 14 de noviembre de 1881 (Barros Arana, 2000:38).

El joven ingeniero inglés llegó a Valparaíso contratado por el gobierno de Chile, el 22 de agosto de 1888, para seguidamente encaminarse hacia el sur con la tarea de "dirigir los trabajos necesarios para la radicación de colonos en el interior de la provincia de Malleco" (Mostny, 1967:9). Su trabajo se centró principalmente en la construcción de caminos, demarcación de hijuelas, planos, etc. Anotaría años más tarde, que el retroceso de la población indígena que pudo constatar era el resultado de 
una serie de factores, donde refería de los estragos de la viruela, la guerra de 1884, la epidemia de cólera de 1887 y la introducción de bebidas alcohólicas en la zona por parte del gobierno de Chile (Latcham 1904).

Este periodo fue especialmente provechoso para Latcham, quien convivió con los araucanos durante cinco años, superando el recelo inicial de la mentada antropofagia de éstos divulgada por obras de ficción. Su estada entre los habitantes del principal pueblo indígena nacional, entre 1888-1890 y 1892-1895 (Latcham, 1924a:8), le permitió interiorizarse de su lengua, sus costumbres, modos de vida y mentalidades. Este conocimiento de primera mano le posibilitó la redacción de sus notables trabajos sobre los mapuches o araucanos. A principios de 1891 se alejó de la Araucanía con destino hacia Santiago. En la capital, su amigo John Smart le señaló la demanda de ingenieros para la construcción del ferrocarril de Santiago a Melipilla. Departiendo con los ingleses, anota Feliú Cruz (1969), se enteró del cariz de la revolución contra Balmaceda. Una guerra civil, que los denominados constitucionalistas o congresistas, imputaban la responsabilidad al Presidente Balmaceda, de haber violado la constitución política al promulgar la ley de presupuesto, sin acuerdo del Congreso, y los gobiernistas o balmacedistas, estimaban que debía imponerse el principio de autoridad presidencial ante el obstruccionismo parlamentarista. Los constitucionalistas contaron con la simpatía de gran parte de la marina de guerra y de los súbditos británicos; los balmacedistas, con la adhesión del ejército y la condescendencia de los EE.UU. Aun cuando se mostró neutral en el conflicto, Latcham fue proclive a los defensores de la causa constitucionalista. Otro amigo, ahora chileno, Javier Fernández Puelma, le animó a impartir clases del idioma inglés. En 1892 comenzó esta dimensión pedagógica en el Instituto Internacional y, además, inició su colaboración periodística con los diarios en lengua inglesa de Valparaíso, como "Chilean Times" en el cual vio aparecer un elogioso artículo sobre el país "Chile as a Field for Emigration". No por eso olvidó la Araucanía la cual visitó entre los años 1892-1895. Nuevamente regresó a Santiago en 1896 retomando su trabajo en el Instituto Internacional y transformándose en el entrenador de fútbol del Athletic Foot-Ball Club, el primer equipo de fútbol de Santiago.

El 1 de abril de 1897 fue nombrado profesor de inglés en el Liceo de La Serena. Acá va a dedicarse tanto a la prospección minera como a recorrer la costa en procura de vestigios arqueológicos, anota Humberto Fuenzalida (1944-1964). La actividad minera estuvo rondando en su vida hasta 1928. En tales afanes pudo terminar su rompecabezas antropológico de Chile y sus habitantes. El norte minero, le brindó conocer el carácter del sufrido pirquinero y barretero en procura de la anhelada veta o filón que le permitiera salir de su miseria. Era la faceta de la actividad productiva que por esos años sostenía a Chile, a través del salitre. Refiere Fuenzalida que, "este contacto terminaba de echar las bases de su afección decidida por Chile y sus habitantes. Hay una fecha en que el señor Latcham deja de sentirse gringo y empieza a ser chileno": 1898 (Feliú Cruz, 1969:11), cuando a los 29 años su alumna 


\section{José Antonio González}

del Liceo se transforma en su esposa, Sara Alfaro. En La Serena colaboró en la "Revista del Norte". En esta urbe colonial, sus dos primeros hijos encontraron la muerte prematura.

ANOTACIONES ETNOGRÁFICAS SOBRE LA SOCIEDAD CHILENA E INICIO DE LOS ESTUDIOS DE ANTROPOLOGÍA

En 1902 regresó a Santiago y, en 1903, publicó su primer trabajo de antropología en el prestigioso "Journal of the Royal Anthropological Institute of Great Britain and Ireland", en el mismo año que fallecía Herbert Spencer, que la publicación estimaba uno de los mayores pensadores de Gran Bretaña. Spencer fue para Latcham un filósofo al que siguió casi devotamente y sus obras, citadas en sus publicaciones, guiaron algunas de sus interpretaciones. Ya figuraba como "Local Correspondent of the Anthropological Institute for Chile", designación otorgada en 1901. En Santiago nacieron sus otros dos hijos.

Importa destacar de esta primera incursión en la antropología física, sus impresiones sobre la sociedad chilena en general, reunidas hacia el final del artículo, donde sostiene aseveraciones que eran compartidas por la élite intelectual del país. Entre éstas, la gravitación del elemento indígena en los sectores populares de la nación, principalmente en el campo, y la ausencia de cualidades en el ámbito laboral y educacional que impedían el progreso del país.

Le sorprendía el bajo nivel intelectual de las clases bajas que, en su concepto, aun podría ser menor que las observadas entre los indígenas. Los sectores populares eran dominados por supersticiones y creencias comunes absurdas; aspectos que fue acopiando durante doce años. Aguardaba hacer algo sobre dichas creencias y su nexo con el folklore popular del país. Apuntaba que en las escuelas se podía apreciar la superioridad de los niños de extranjeros sobre los nativos y esta mejor preparación se hacía notar en el país: "This superiority extends to later life; in commerce, science, art, politics and general enterprise, the most celebrated names are frequently foreign" (Latcham, 1903:175).

Apelando a su experiencia de cinco años como profesor en liceos conclúa que la causa de este panorama socio-racial era la naturaleza apática de los habitantes nativos, más inclinada a la rutina que a tomar la iniciativa en el trabajo o en el pensamiento. Importaba a su criterio, casi como proyección de lo anotado, que la embriaguez como la falta de honradez tanto de palabra como de obra, eran los vicios nacionales que afectaban a la mayoría de la población. Se hablaba muy mal el español, con inclusiones de voces locales y palabras indígenas. La falta de una formación moral tanto en el hogar como en la escuela contribuía a este estado de degradación que ni siquiera la religión podía contrarrestar. Si bien la religión católica era la mayoritaria, "but among the upper classes it exists in little more than name, except among the women", en las clases bajas rurales la religión había degenerado en una especie de fetichismo. Dudaba si "among the very lowest order of the population, 
the intellect is sufficiently developed to comprehend the mysteries of a highly organized religion, such as that of the Roman Church, which belongs, metaphysically, to a high state of civilization" (Latcham, 1903:175).

Años después, en sus celebradas conferencias sobre antropología 1914-1915, sostuvo una crítica sobre la pervivencia de determinadas costumbres coloniales que se apreciaban en los habitantes rurales y de las clases bajas. Cuestionó que la supresión de algunas instituciones coloniales, hubiese aliviado las condiciones del bajo pueblo. Todo esto delataba el "conservantismo", muy arraigado en el hombre, que se notaba en la gente del campo (Latcham, 1915):

"El hombre es por naturaleza conservador. Sospechoso y hasta enemigo de lo nuevo, esquiva y repudia las ideas y costumbres extranjeras, custodiando celosamente las suyas y aun ocultándolas de los demás... Esto lo vemos en todo orden de ideas, y es una clave para descifrar muchos enigmas de la sicología. Lo notamos en las costumbres religiosas, en que los cultos, o al menos su forma exterior, tienen que modificarse al ser propagados en nuevas regiones y consentir que se ingerten (sic) en ellos costumbres difíciles o imposibles de desarraigar. Ejemplo de esto lo hallamos en los bailes a la Virgen, comunes entre las poblaciones rurales de Chile y otros países de SudAmérica... La emancipación del esclavo y la libertación (sic) de la servidumbre se efectuaron sólo parcialmente y en muchas partes aun existen sólo en el nombre... Las encomiendas, suprimidas hace más de un siglo, fueron reemplazadas por el inquilinaje; lo que en principio no fue más que otro nombre para la misma cosa, puesto que no cambió en mucho la condición de los agraciados, quienes por la fuerza de la costumbre, continuaron en su mayor parte en las haciendas o estancias en que se hallaban. Todavía, especialmente en las localidades más apartadas de las grandes poblaciones, se encuentran los descendientes de los encomendados ocupando los mismos parajes, dedicados a las mismas faenas, siguiendo las mismas costumbres, y soportando con resignación y tranquilidad las mismas imposiciones y vejámenes que sus antepasados. Este conservantismo se nota en todos los pueblos y en todas las edades, en mayor o menor grado, más especialmente en la gente del campo. El campesino chileno ¿Cuánto ha avanzado desde la época colonial? ¿No conserva las mismas supersticiones y costumbres de antaño? ¿Son diferentes los ranchos de ramas y totora que habita? ¿El ajuar que usa ha mejorado? ¿Su indumentaria de ojotas, poncho, faja, etc., no es la misma que antes? ¿No se muestra todavía enemigo acérrimo de las innovaciones, usando de preferencia su arado de palo, trillando con su manada de yeguas y prefiriendo su almud, fanega, arroba, vara y reales a las más modernas y fáciles medidas y monedas?" (62-63).

Las conferencias de Latcham ilustraron a los sectores intelectuales de Santiago sobre los avances de las ciencias dedicadas al estudio de las sociedades humanas del pasado. También, el arqueólogo inglés les indicó determinadas deficiencias que había observado en nuestro país en el ámbito de la salud pública, 


\section{José Antonio González}

como el atraso de controlar determinadas enfermedades, como la peste bubónica o la viruela, ya desterradas en los países industrializados. La frecuencia de la aparición de estas enfermedades infecciosas había causado enormes mortandades. Reparó en otra enfermedad: "el cretinismo, o detención de las facultades intelectuales, físicas y morales (que) es incurable, en Chile existen varios parajes donde estas enfermedades son endémicas; entre otros el Cajón de Maipo, el valle interior de Elqui, el valle de Cogotí, el valle de Choapa, etc., donde llaman tontos a los cretinos" (Latcham, 1915:54-55).

Antes de su instalación definitiva en Santiago, Latcham adquirió los principales estudios y manuales europeos sobre las tipologías raciales, craneometría, etnología, etc., de autores en boga, como los franceses Paul Broca o Joseph Deniker, el alemán Franz Pruner Bey o el irlandés August Henry Keane. Fueron los años pivotales de autodidacta. Llegó a conformar una rica y variada biblioteca en diversas disciplinas de las ciencias sociales. Lee y se compenetra en las crónicas tanto chilenas como peruanas de los siglos coloniales, desde 1893 (Latcham, 1924:303). Su vivo interés y curiosidad por el entorno natural y social donde le condujo su profesión de ingeniero lo plasmó en sus cuadernos de campo, que registraron sus observaciones. En sus libretas consignó sus intuiciones e interpretaciones de los variados sucesos de los que fue testigo. Como hombre metódico, riguroso por su formación ingenieril, se inclina por acopiar hechos que le llaman la atención, clasificando cuidadosamente los objetos, cotejando hipótesis que circulan sobre las poblaciones indígenas actuales y del periodo prehispánico. Estima que su acción puede contribuir a arrojar luz sobre la controversia de los habitantes primitivos de esta parte del continente (Latcham, 1904a:234).

La experiencia de su permanencia en tierras araucanas le convenció tanto de la reversión del pueblo araucano en cuanto a la disminución de su población — por las razones ya anotadas - como asimismo bocetar sus anotaciones sobre las características antropológicas de éste. Si bien va a indicar que por lo general —como eran los planteamientos dominantes entonces - se ha denominado a la población nativa del país como araucana, desde el desierto de Atacama hasta las islas de Chiloé, ésta se diferencia de acuerdo a su ubicación geográfica. En el norte, los Moluches, gente de la guerra; Mapuches, en las provincias de Malleco y Cautín, pueblo de la tierra; en los valles de los Andes, Pehuenches, gente de los pinos; y al sur, en las provincias de Valdivia y Llanquihue, los Huilliches. Cabe indicar que las anotaciones de antropología física de Latcham, en cuanto a estatura, fecundidad, le van a encaminar a disentir de algunas opiniones sostenidas por Tomás Guevara, un destacado profesor, antropólogo, cuyo saber del pueblo araucano también era de primera fuente, por su larga estancia en su zona geográfica (Latcham, 1904). Sostiene Grete Mostny, que ya por estos años de 1904 a 1912, se debe rastrear en la obra de Latcham los elementos de su teoría sobre la formación del pueblo araucano, donde 
figuran su artículo del "Journal" y una colaboración en la "Revista Chilena de Historia y Geografia” (Latcham, 1912).

La inclusión de su artículo en esta última revista puso de manifiesto que su círculo de amistades en Santiago le había abierto las puertas hacia las sociedades científicas, cuyo primer contacto fue con Carlos E. Porter y su "Revista Chilena de Historia Natural”, en la que contribuyó entre 1903-1939 con 26 estudios variados, según Feliú Cruz.

LATCHAM Y SU RELACIÓN CON LA COMUNIDAD CIENTÍFICA NACIONAL. SU VISIÓN ANTROPOLÓGICA

Su residencia en Santiago le permitió vincularse decididamente a los núcleos intelectuales tanto de las ciencias naturales como históricas. Con Porter, frecuentó el Museo de Historia Natural; en la Biblioteca Nacional hizo amistad con Ramón A. Laval, sub-director; la presencia de Valentín Letelier en la Rectoría de la Universidad de Chile (1906-1911), le brindó el imprescindible apoyo y la edición, a partir de 1909, de sus estudios de mayor aliento, que le prodigó asimismo Domingo Amunátegui Solar, desde ese alto cargo universitario, entre los años 1911-1923.

La Sociedad Chilena de Historia y Geografía, fundada por Enrique Matta Vial, el 21 de septiembre de 1911, le contó entre sus primeros y principales miembros. Se le encargó la organización de una de sus secciones, la de Antropología, Arqueología y Etnología, que conformaban la Prehistoria. Desde esa tribuna, Latcham realizó una interesante labor de extensión cultural, a través de sus conferencias sobre la antropología, arqueología y la etnología. En los salones de la Biblioteca Nacional entre los años 1914 y 1915 Latcham impartió sus lecciones. La antropología, hacía notar Latcham, como ciencia nueva debía pasar por muchas vicisitudes, algunas bastante complejas, trabajando con métodos que necesariamente debían ser comparativos. No obstante, las dos escuelas dominantes, la ortodoxa y la evolucionista, no lograban llegar a consenso sobre la aparición del hombre: "Mientras la una quiere sostener la cronología mosaica de seis o siete mil años, la otra considera este periodo del todo insuficiente para explicar los cambios radicales que se notan en la constitución del hombre, su dispersión por todo el mundo y otros problemas que presenta la Antropología... Es muy difícil conciliar las pretensiones de ambas escuelas porque carecen de una base fundamental común, y partiendo de diferentes puntos de vista, interpretan los mismos hechos cada una a su manera" (Latcham, 1915:7).

En el marco de las actividades de la Sociedad Chilena de Historia y Geografia, Latcham colaboró con el encargo del gobierno a la Sociedad, en agosto de 1914, de traducir y publicar en castellano "las obras escritas en otros idiomas que estimara del caso a fin de continuar la Colección de autores extranjeros relativos a Chile, para cuyo fomento acuerda todos los años cierta suma" (Smith, 1914:III-IV). 
Latcham se enfrentó a dos ideas muy arraigadas en el ambiente cultural nacional: el de la homogeneidad racial de nuestra prehistoria y la exclusión de los pueblos prehispánicos del norte chileno (Orellana, 1996; Parentini, 1996).

Barros Arana (2000), en su citada Historia General de Chile, había formulado la tesis de la homogeneidad racial de los pueblos prehistóricos chilenos y Tomás Guevara, en sus diversos estudios sobre los araucanos, había defendido dicha postura. Empero, ambas posiciones etnológicas ignoraban el conocimiento de los pueblos indígenas al norte de Copiapó, fuesen de asiento marítimo o continental.

Latcham, al igual que lo que hizo el antropólogo norteamericano Ales Hrdlicka entre los años 1910-1912 con las teorías del paleontólogo argentino Florentino Ameghino respecto a la antigüedad del hombre en América del Sur, acometió la empresa científica de refutar las argumentaciones tanto de Barros Arana como de Tomás Guevara.

Las ideas de la homogeneidad sostenidas por Barros Arana eran las enseñadas en las escuelas y liceos sin mayor crítica. Latcham estuvo consciente que rebatir al principal historiador chileno le podría acarrear más de algún sinsabor. Pero aquello no le arredró. Ya en el Cuarto Congreso Científico ( $1^{\circ}$ Pan-Americano) celebrado en Santiago, en 1908, cuestionó severamente a "Barros Arana, fundador de la escuela monogenista de la cultura", en su estudio "Antropología Chilena", que vio luz en la Revista del Museo de La Plata, en 1909. Y, nuevamente en 1924, volvió sobre el asunto, cuando escribió en su obra Organización social y creencias religiosas de los antiguos araucanos (1924), que mucho se había escrito en estos últimos veinte años pero en base a generalizaciones pero sin tener datos verídicos suficientes para justificar tales procedimientos o hacerlas coincidir con teorías premeditadas. Ideas provenientes de obras del clero ya con preconcepciones sobre las ideas de los araucanos y la falta de términos adecuados, ayer y hoy, para explicar las ideas de los araucanos, habían conformado un panorama erróneo sobre este pueblo. No ponerse en la mentalidad del indio constituía otro obstáculo, pues no tenía desarrollada la abstracción o las ideas espirituales como lo entendían los occidentales (Latcham 1924a). Y entrando en la etnología, Latcham explayaba su fundamento contra la homogeneidad:

"La supuesta homogeneidad de los indios chilenos era un mito fundado en razones lingüísticas... En trabajos anteriores [alude a la Antropología Chilena de 1908 y Elementos indígenas de la Raza Chilena de 1914] dejamos constancia de haber existido en la zona referida, dos pueblos antiguos que habitaban la costa y los llanos centrales, encontrándose mezclados en las inmediaciones de las caletas abrigadas y desembocaduras de los numerosos ríos. Uno de ellos, el más antiguo, y quizá autóctono, era pueblo de pescadores y a ellos se deben los conchales que se encuentran esparcidos por las playas del mar. Su cultura era baja. No se dedicaban a las faenas agrícolas... Posteriormente llegó a la zona, desde el norte, otro pueblo más culto, que se extendió por el litoral y valle central hasta el Seno de Reloncaví, y el cual, al 
parecer, pasó también a las islas del Archipiélago de Chiloé, donde se fusionó con los Chonos, que la habitaban entonces, formando el elemento que llamamos Chilote... Este pueblo puede identificarse con aquel que ocupaba las provincias centrales de Chile en tiempo de la conquista de ellas por los Incas... y de él era la lengua que se hablaba en todo el país y que llamamos araucana... En la cordillera y especialmente en el valle del Alto Bío Bío habitaban, en la misma época, otro pueblo de cazadores nómadas, cuyas correrías deben haberse extendido a las pampas argentinas... Se les ha llamado pehuenches, porque la zona que ocupaban es la de los bosques de pehuenes o pinos (Araucaria Imbricata), cuyos piñones hasta hoy forman uno de los principales alimentos. Estando así las cosas, llegan, de las pampas argentinas, sucesivas migraciones de un nuevo pueblo, distinto en cultura y en caracteres físicos a aquellos que ocupaban el territorio... se esparció por los campos entre el Toltén y el Bío Bío, extendiéndose más tarde al norte de este último río hasta el Itata. Para el efecto de distinguir este pueblo, le llamaremos moluche, gente de guerra. En parte se amalgamaron con los antiguos habitantes, especialmente en la región de la costa y en ambas faldas de la cordillera de Nahuelbuta hasta el Cautín" (17-20).

Tomás Guevara habíase dado a conocer en 1898 con la publicación en los Anales de la Universidad de Chile de su Historia de la Civilización de la Araucanía, que después se transformaría en una serie de volúmenes entre los años 1898-1902. La competencia de Guevara en el tema de los araucanos estaba avalada en varias obras, como Costumbres judiciales $i$ enseñanza de los araucanos, de 1904; Psicología del pueblo araucano, de 1908; La mentalidad araucana, de 1916; Las últimas familias $i$ costumbres araucanas, de 1913; Historia de Chile: Chile prehispánico, de 1925 y 1929. Los juicios de Guevara encontraron una fuerte réplica en el nacionalismo chileno, que se graficó en Nicolás Palacios y su Raza Chilena, de 1904 (González 2009). Pero la crítica de Latcham se dirige hacia otra dirección, donde la discrepancia sobre el origen de los araucanos conlleva en cierta forma la afirmación de la no homogeneidad étnica de los habitantes del país. Empero Latcham respetó la producción de Guevara en diversos temas que trató sobre los araucanos, "en esta materia está bien versado el autor, y debemos a su pluma diez o más volúmenes en que presenta el pueblo araucano en las más variadas fases de su historia y su sociabilidad" (Latcham 1928 45), pero el asunto de los orígenes fue el principal escollo. Éste, como hemos visto en el estudio de Latcham de 1924, se profundizó cuando Guevara dio a conocer su Chile Prehispano (Latcham, 1928:47-90-91).

Latcham, en sus obras posteriores, siguió manteniendo sus teorías sobre la no homogeneidad y el origen de los araucanos. La controversia sobre este último tema prosiguió hasta fines de la década de 1920, tanto con el Dr. Aureliano Oyarzún (Latcham, 1927) como con Tomás Guevara (Latcham, 1930). El debate abierto por Latcham ha tenido partidarios como detractores en el campo de la arqueología (Mostny, 1967:13; Keller, 1952:LXI; Orellana, 1996:154; Parentini, 1996:27-40; Núñez, 2001). 
Si hacia 1908 Latcham se había atrevido a exponer sus planteamientos, también soplaban vientos que auguraban un mejor ambiente cultural-científico en el país. Tanto Fuenzalida como Feliú Cruz, han subrayado que los progresos intelectuales que experimentó el país en torno al centenario de la república se debió tanto a personalidades claras y fuertes en tentar investigaciones científicas como a la formación de variadas sociedades al respecto. En este sentido, hubo hacia 1911 la confluencia de dos acontecimientos de suma importancia para el giro de la investigación arqueológica: la decisión gubernamental de crear un Museo de Historia Natural y la contratación del sabio arqueólogo alemán Max Uhle.

La creación del Museo de Historia Natural, el 3 de mayo de 1911, se tradujo que su sección de Prehistoria se encargara al arqueólogo Uhle, quien llegó hacia fines de 1911 y logró transformar la sección en Museo (Alegría 2004). El Museo de Etnología y Antropología en Santiago, posibilitó a Max Uhle sus exploraciones por el territorio nacional hasta el año 1919, aunque oficialmente en 1916 concluyó su contrato (Latcham, 1928a 7; Breton, 1919 140-143; Mostny, 1964). Uhle y Latcham estuvieron al frente, escribe Orellana, de la Sección de Antropología, Arqueología y Etnología, siendo dirigida por el alemán y secretario el inglés.

También habrá que enfatizar que la presencia de Uhle, como refiere Latcham en La Alfarería Indígena Chilena, significó el comienzo de "otra era en el estudio de la arqueología del país". Y aquello se apoyaba en la producción escasa y de desigual valor que existía en nuestro país en el área de la antropología, como pudo manifestarlo en 1910, al prologar un importante trabajo de su amigo Carlos E. Porter (1910):

"Una de las dificultades más graves con que puede tropezar el investigador, en cualquier ramo de la ciencia, es la de no tener noticia de todo lo que se ha publicado anteriormente sobre el tema o los temas en que está interesado. En Chile se nota todavía mucha deficiencia en esta materia, y se pierde un tiempo precioso en tener que revisar catálogos (cuando estos existen) en las bibliotecas, hojear revistas y periódicos, o consultar las listas de publicaciones en general de las casas editoras. Para nuestros estudios antropológicos y etnográficos, hemos lamentado, en muchas ocasiones, la falta absoluta de alguna bibliografía que nos diera a conocer lo que se había escrito, en el país, sobre esta cuestión" (147-148).

La estada de Uhle en Santiago fue a nuestro entender, fundamental para Latcham, en dos sentidos. Por un lado, le actualizó del conocimiento sobre la prehistoria peruana, dado que Uhle había descollado previamente en el antiguo virreinato poniendo los cimientos de los estudios arqueológicos y, por otro, le hizo llamar la atención sobre la importancia y antigüedad de los habitantes de la costa.

Latcham se había adentrado a examinar el alcance de la dominación incaica en Chile en un artículo publicado en 1908. Al año siguiente había dado a las prensas "El 
comercio precolombino en Chile y otros países de América", donde llevó a cabo una breve aproximación al asunto.

$\mathrm{Su}$ inserción en los ambientes científicos tanto nacionales como internacionales le permitió granjearse de una buena reputación en el campo arqueológico como antropológico. A la fecha, figura como miembro correspondiente de The Royal Anthropological Institute of Great Britain and Ireland, miembro activo de L'Alliance Scientifique Universelle, de la Societé des Américanistes de París, de la Societé Scientifique du Chili, miembro activo de la Sociedad de Folklore Chileno (Laval, 1915:XXVII). En 1911 se incorpora a la Sociedad Chilena de Historia y Geografía.

\section{LATCHAM Y SU APORTE AL CONOCIMIENTO ARQUEOLÓGICO DE LOS PUEBLOS DEL NORTE DE CHILE. LA NUEVA FRONTERA ÉTNICA}

Para la época en que Latcham va a incursionar el desierto de Atacama, la región de Antofagasta, junto a la de Tarapacá, vivía el ciclo del salitre que se había traducido en un poblamiento de la depresión intermedia con instalaciones industriales y campamentos - las oficinas - expandiendo la frontera productiva y demográfica de Chile, después de 1883. El fisco nacional se mantenía de los tributos salitreros. El arqueólogo inglés nos va a descubrir en la provincia de Antofagasta la frontera étnica de los atacameños, los cuales se habían hecho visibles en determinadas faenas del mineral de Chuquicamata, a partir de 1915.

Con ocasión del Congreso Científico Internacional de Buenos Aires, celebrado en julio de 1910, presentó su estudio sobre los changos en las costas de Chile, pasando revista a toda la bibliografia habida sobre el tema, desde los cronistas hasta los autores actuales que habían llevado a cabo misiones científicas.

Latcham se apoya en sus recorridos tanto en las costas de las provincias de Coquimbo como de Atacama, para exponer algunas visiones ante las obras consultadas. La escasa referencia a los changos en los textos nacionales se debía a que la etnia mencionada se localizaba en el desierto de Atacama, donde "ocupaba el litoral de una región que en tiempos de la colonia era casi completamente desconocida; situada entre los dos virreinatos de Chile i Perú; bordeando el desierto casi intransitable"; estima que los autores se han equivocado al plantear una sola entidad étnica para los changos, cuando los habitantes antiguos y modernos, "han pertenecido a varias razas, cuyas costumbres, grado de cultura i aptitudes han sido mui (sic) parecidas, siendo por el contrario mui (sic) diversos sus caracteres físicos" (Latcham, 1910:5-6).

El francés Eric Boman había precisado, con acierto, en su "Antigüedades de la Rejión Andina de la República Argentina i del desierto de Atacama”, (Boman, 1991)que la descripción llevada a cabo por Juan Lozano Machuca refiere que los changos que habitaban la costa entre Cobija en el norte y Huasco por el sur, se ubicaban en buen número en la ensenada de Atacama (Cobija); afirmación que 


\section{José Antonio González}

Latcham, de modo equivocado, va a refutar que "el actual puerto de Cobija (antes Lamar) sea el antiguo puerto de Atacama, pero opinamos que este se encontraba más al norte"(Latcham 1910 20). El planteamiento de Latcham fue que los antiguos pobladores conformaban el paleo-americano que se fusionó con otra etnia dando lugar a los changos. Los estudios de los cráneos de cementerios lo llevaban a dicha hipótesis. Le llamaba la atención que en las costas de Antofagasta se hallara un gran número de objetos de madera de distintas formas y para variados usos.

Si se consideran las observaciones de Latcham sobre la cantidad de objetos recogidos tanto por Aichel como por la Mission Francaise dans le Désert d' Atacama, a la cual pertenecía Eric Boman, y su traslado a Europa, se comprenderá el júbilo experimentado con la creación del Museo de Historia Natural (González, 2010).

$\mathrm{La}$ atención por el norte prosiguió en el decenio de 1910. Uhle habíase internado en el desierto de Atacama excavando en Calama en 1912 y aportando otras especies al Museo de Historia Natural (Núñez, 2010). A su vez, en Taltal, otro arqueólogo, Augusto Capdeville, había abierto otro campo de exploración.

Como evocaría Capdeville, "el 18 de septiembre de 1914 por primera vez me dediqué a exploraciones arqueológicas", las que durarían diez años. Un hecho de importancia puso a Taltal en el escenario de los yacimientos arqueológicos chilenos: el viaje de Capdeville a Santiago, en el verano de 1915, "donde se contactó con las principales personalidades de la arqueología chilena como Ricardo Latcham, Aureliano Oyarzún, Max Uhle y Carlos Porter, dándoles a conocer el trabajo arqueológico realizado en Taltal y sus primeras conclusiones" (Núñez, 2008:15). Con el conocimiento de los objetos líticos de puntas de lanzas y flechas, Latcham difundió dicho descubrimiento bajo el título de "Una estación paleolítica en Taltal" en la Sociedad Chilena de Historia y Geografía, que posteriormente daría a las prensas, en la "Revista" de la institución, tomo XIV, de 1915. Tales resultados también fueron analizados por Aureliano Oyarzún y Max Uhle, al año siguiente.

El norte atisbado desde La Serena con irregulares excursiones hacia Copiapó, quedaba superado por el horizonte del denominado norte grande, las nuevas provincias de Tarapacá y Antofagasta, que Uhle ponía de súbito con una importancia arqueológica insospechada, tanto hacia la costa como hacia el corazón del desierto de Atacama. Latcham no dejó pasar el desafío que significaba la antigüedad del hombre tanto en Taltal como en Calama. Hagamos un alto en el tiempo y veamos cómo actúa Latcham al respecto.

Latcham se involucró en la temática, primeramente, con un artículo de difusión en 1925 - "The Atacameños of Northern Chile" - publicó en Valparaíso en "The South Pacific Mail". En 1927 dio a publicidad una serie de artículos en torno a los tubos para aspirar rapé (Latcham, 1927a), las influencias chinchas en la alfarería (Latcham, 1927b), de la cultura de Tiahuanaco (Latcham, 1927c), retomando en 1927 sus investigaciones sobre la alfarería de los antiguos atacameños (Latcham, 1927d), y la alfarería negra de la región atacameña (Latcham, 1927e). 
Al año siguiente, publicó La Alfarería Indígena Chilena, cuyas informaciones sobre las culturas del norte grande provenían de las noticias de Uhle y de Capdeville. Apoyado en los autores en comento, Latcham en 1928 trazó un cuadro de la prehistoria chilena, donde la cultura atacameña quedaba incorporada plenamente. En su opinión, el historiador, "poco a poco, se ha ido convenciendo que el periodo verdaderamente histórico en la evolución de cualquier pueblo o nación, es decir, la época en que principió una documentación escrita, es la parte más breve y con frecuencia la menos importante de su desarrollo" (Latcham, 1928b Introducción).

En 1928 fue un año de reconocimiento. Ricardo E. Latcham fue nombrado Director del Museo de Historia Natural, cargo que desempeñó hasta su muerte en 1943 (Mostny, 1980:135). Cabe acotar que por la importancia y antigüedad del Museo, Latcham acostumbró a destacar en sus publicaciones que era Director del "Museo de Historia Nacional de Chile", quizá, por ese sentido de "idea de comunidad" nacional que transmitieron tanto Max Uhle y Martin Gusinde, imbuidos en el sentido museológico alemán, donde los disímiles objetos de los pueblos indígenas que conservaba el Museo, en vez de constituir muestras de culturas inferiores por el contrario eran los antecedentes primigenios del pueblo chileno (Alegría, 2007).

Ese mismo año, refieren sus biógrafos, fue nombrado académico de la Universidad de Chile para servir la cátedra de Historia del Arte y al año siguiente la cátedra de Arte Indígena Americano. Mostny, agrega, "ese mismo año la Universidad de Chile decidió la creación de la Facultad de Bellas Artes, confiriéndose a Ricardo Latcham el honor de ser su primer decano" (Mostny, 1967:14).

Con Latcham, el espectro del saber sobre la cultura atacameña se abre hacia la monumentalidad arquitectónica, sin descuidar las excavaciones arqueológicas en distintas áreas de la precordillera atacameña. Ya lo había advertido en su obra sobre la Prehistoria de Chile (1928), cuando al mentar en el capítulo V "Los indios atacameños de las provincias del norte", afirmó que: "Falta mucho para investigar. La arqueología de la región descrita apenas se conoce".

El destacado arqueólogo va a redactar dos títulos que estimamos abrieron definitivamente la senda para la legitimación de la cultura atacameña, en cuanto a la certeza de poder diferenciarse de otras culturas y ofrecer un cuadro cultural donde la arquitectura tanto residencial como de fortaleza no estaba ausente - aspecto diferencial con lo observado hacia el sur de Chile- que reforzaba una de las bases auténticas del patrimonio territorial y étnico.

Uno va a estar referido a las construcciones vinculadas con la cultura atacameña. Para el propósito de recabar información in situ emprendió un viaje en mayo-junio de 1935 junto al geólogo Humberto Fuenzalida hacia el desierto de Atacama, visitando Calama, Chuquicamata, Chiu-Chiu, Turi, Aiquina, Lasana, San Pedro de Atacama y Toconao. Las excavaciones arqueológicas arrojaron buenos resultados, siendo los objetos hallados remitidos al Museo. Visitaron - escribe en la 


\section{José Antonio González}

Memoria de 1935 - "las ruinas de varias ciudades prehistóricas, jamás estudiadas, y a su regreso a Santiago dieron conferencias en que proyectaron las numerosas fotografias que tomaron de estos lugares" (Latcham, 1935:189). Las anotaciones de campo y la lectura crítica de los cronistas, permitió a Latcham echar por tierra la creencia generalizada que en el territorio chileno no se encontraban vestigios arquitectónicos anteriores a la llegada de los españoles. Las pocas referencias a ellas en las crónicas las vinculaban al tiempo de la ocupación incaica o bien al despuntar el siglo XVI, lo cual venía a corregir. En su concepto, había una idea errónea al respecto, dado que en el norte chileno existían una serie de ruinas de antiguas ciudades no sólo del periodo prehispánico, sino también pre-incaico. La importancia de este conjunto de edificios permitía hablar de ciudades, independiente del estado de conservación. Sus observaciones las dio a conocer en las páginas del "Boletín del Museo de Historia Natural" y de "American Anthropologist", a petición de su editor (Latcham, 1936-1936a).

En ambas publicaciones de las ciudades prehispánicas, Latcham describía adjuntando las correspondientes fotografias de los lugares donde posó tambiénChiu-Chiu, Lasana, llamando poderosamente su atención las habitaciones y las murallas de su pucará, prosiguiendo con Turi y San Pedro de Atacama. Concluía el Director del Museo Nacional de Historia Natural, que en otras partes de la región existían otras ruinas de ciudades no examinadas, tan importantes como las que él describía. Todo esto demostraba que la antigua cultura atacameña era más desarrollada y avanzada de lo que se suponía (Latcham, 1936a:58).

El artículo en cuestión - más una exposición de sus excavaciones (Latcham, 1936b; Le Paige, 1968-1969) - y su fundamental libro Arqueología de la Región Atacameña, que lo había terminado hacia 1935, pero que debió viajar al desierto para disipar algunas dudas, en 1937 (Latcham, 1935:188;1937:145), lo que explica su edición recién en 1938, constituyeron los aportes más significativos de Latcham al conocimiento de la cultura atacameña. El libro fue bien acogido por la comunidad científica. Latcham exponía en el libro en referencia:

"Si exceptuamos la araucana, que ha sobrevivido hasta nuestros días, la más conocida de estas antiguas culturas y una de las más interesantes, es la del pueblo conocido con el nombre de atacama o atacameño... En tiempos prehispánicos, uno de sus asientos se hallaba en los contornos del Salar de Atacama, cuya principal población se llamaba Atacama (hoy San Pedro de Atacama), y es debido a estos hechos que recibió el nombre de atacameños. Sin haber logrado una cultura tan adelantada como algunas de las del antiguo Perú, habían hecho considerables progresos en muchas de las artes e industrias. Hablaban un idioma propio, el cual, hasta ahora, no se ha podido concordar con ningún otro. Esta lengua se ha llamado kunza" (6). Latcham, después del libro glosado, redactó tres artículos específicos sobre sus hallazgos en la zona norte (Latcham, 1939, 1940, 1942). 
Nombrado Director del Museo de Historia Natural, en 1928, ese mismo año dio a publicidad dos libros muy apreciados por él: La alfarería indígena, que dedicó a José Toribio Medina, "verdadero iniciador de los estudios arqueológicos en Chile", y que el gobierno tenía previsto presentarlo en la Exposición de Sevilla, ese mismo año, lo cual le exigió un esfuerzo mayor, según estampó en él (Latcham, 1928a:8).

En cuanto al segundo libro La prehistoria chilena, Latcham sostuvo que el público y el hombre medio no se conformaban con meras descripciones, aspiraban a que se les presentara las correlaciones de causas y efectos, el por qué de las cosas, superando la mera enunciación de hechos y de fechas. Esta era la nueva exigencia de los "estudios históricos y no la historia", pues la realidad iba señalando que el periodo "verdaderamente histórico... la época en que principió una documentación escrita, es la parte más breve y con frecuencia la menos importante de su desarrollo" (Latcham, 1928b:3).

La prehistoria era la ciencia que reunía los datos que aportaba la arqueología. Y esta demostraba para el friso prehispano de Chile, la no existencia del monogenismo racial, como tampoco, "que toda la cultura hallada en el país por los primeros españoles era nueva, aportada por los incas cuando invadieron Chile unos pocos decenios antes de la conquista Española" (Latcham, 1928b:5).

Estos errores realmente irritaban a Latcham, pues eran los propalados en los manuales de estudios de los escolares de todos los niveles. La crítica, a veces no tan velada, era la poca adecuación de la enseñanza a los avances de las ciencias correspondientes. Ya Max Uhle como Martin Gusinde habían desvelado la arqueología y la etnología de los extremos del país, encontrándose para la zona norte - el norte grande - relaciones con las culturas de las regiones circundantes del Perú, Bolivia y el norte de la Argentina.

En su obra acogió la periodización que entregó Uhle para la región del norte como asimismo la existencia de una influencia, por lo menos hasta Taltal según las excavaciones de Capdeville, de la cultura Chincha, la cual dio origen a la cultura Chincha-Atacameña (Latcham, 1928b:36). Apunta a distinguir ya una "Cultura Diaguita" (Latcham, 1936c:193-194).

$\mathrm{Su}$ experiencia en el norte chileno le confirmó en un juicio que se había ido formando, en cuanto que los pueblos no estaban aislados; siempre hubo contactos desde otras regiones. Aquello era distanciarse de la rigidez de la teoría evolucionista, de una evolución única, y acoger líneas múltiples de desenvolvimiento, pero tampoco asimilar como advierte Orellana - las ideas "de la escuela cultural - histórica de los etnólogos católicos" (Orellana, 1996:138;2001:57). El tratamiento de las influencias y periodizaciones en la evolución de la arqueología en nuestro país, no siempre ha sido coincidente en 


\section{José Antonio González}

todos los autores (Orellana, 1996:2001; Gundermann, 2009; Núñez, 2001). Empero, anotamos, Latcham fue ecléctico en cuanto a la teoría. Si se inclinaba o insinuaba algún marco teórico de escuela antropológica, seguidamente consignaba alguna variante al mismo. Una expresión al respecto que grafica lo expuesto se tiene cuando al estudiar las creencias religiosas del imperio incaico, señala que casi intuitivamente se piensa en la raza Maya que pudo haber influido y ser el vínculo tanto de este imperio como del "imperio mejicano". Y escribe de modo inequívoco, avalando nuestro aserto (Latcham, 1929):

"Debemos conformarnos entonces con la hipótesis de una tendencia natural en el hombre, de seguir ciertas leyes evolucionarias en el desarrollo de las etapas consecutivas de sus pensamientos religiosos, los que parecen desenvolverse de idéntica manera, dondequiera que sea, cuando las condiciones de la vida psíquica se asemejan, aproximándose más a medida que coinciden estas condiciones y variando en proporción a sus divergencias... No queda duda alguna que en ambos casos [el impero inca y el imperio mejicano], tanto la cultura material como la religión eran autóctonas. Su desenvolvimiento tuvo lugar, sin contactos y sin que un pueblo tuviera conocimiento del otro, cada uno en su ambiente natural, aun cuando ambos pueden haber recibido influencias directas o indirectas de la superior cultura de los mayas" (10).

Esta concepción de préstamos e influencias de pueblos en otras culturas la abrazó, podría decirse, tempranamente Latcham. Tal concepción, conjeturamos, comenzó a dibujarse con claridad durante la presencia de Max Uhle. Lo que aseveramos nos lleva hacia la otra influencia del arqueólogo alemán: el mundo incásico. La visión que estructuró sobre el imperio incásico comienza hacia el año 1914, cuando compartió con Uhle en la Sección de Antropología, Arqueología y Etnología de la Sociedad Chilena de Historia y Geografía, y acopió los materiales imprescindibles sobre el dominio inca. Aquello le estimuló a dar a publicidad en 1924 su Organización social y creencias religiosas de los antiguos araucanos.

Fue el estudio de los indígenas chilenos el que afianzó en Latcham la convicción que, para comprender a éstos de manera satisfactoria, debía levantar investigaciones comparativas con los otros vecinos, "porque se influenciaban de tal manera, unos a otros, en tantas distintas manifestaciones de la vida, que, para comprender todos estos vínculos, era preciso ampliar el estudio y revisar los fundamentos de todas las diferentes culturas andinas" (Latcham 1928c:3-4). En otra monografía, sostuvo igual parecer (Latcham, 1936d:1).

Anotemos que las magistrales monografías sobre la civilización incaica, le hicieron acreedor del reconocimiento de las universidades de La Plata y de Lima, las cuales le nombraron Doctor Honoris Causa. Era el año 1939. Aprovechó la ocasión el gobierno de Chile, al cumplir cincuenta años de 
residencia en el país, el 9 de noviembre de 1939, para conferirle la Orden al Mérito en el grado de Comendador y la Facultad de Filosofía de la Universidad de Chile lo nombró miembro académico y honorario.

La salud de Latcham mostraba un deterioro hacia fines de la década de 1930. No obstante, no amilanó su espíritu que lo llevó a participar en el XXVII Congreso Internacional de Americanistas en Lima, en 1939. Se interesó, al despuntar la década de 1940, por la cultura El Molle que descubriera su amigo Francisco L. Cornely. Para el año 1943 su quebrantado estado corporal, no impidió su postrero esfuerzo de colaborar para el Catálogo de la Exposición Americana de Artes Populares y dejó un estudio, inédito, sobre la Cultura Diaguita. Falleció el 16 de octubre de 1943.

\section{CONCLUSIONES}

Latcham fue un arqueólogo que revisó críticamente la homogeneidad racial de la base étnica chilena y un gran impulsor de la arqueología bajo parámetros científicos. En su faceta de etnógrafo prestó atención a la profunda desigualdad de la sociedad chilena que, a su juicio, derivaba de las influencias coloniales y del estado de ignorancia del bajo pueblo. En tal sentido, reparó en los vicios que impedían el desarrollo material del país, como eran la apatía, el poco esfuerzo individual y el sentido de responsabilidad. El cientista inglés develó la realidad social del país durante el denominado periodo parlamentario, enfatizando con sus observaciones, comúnmente silenciadas en sus biógrafos, no solamente la desigualdad entre las clases sociales, entre los mundos urbano y rural, sino en la correlación que debía existir entre una educación que apuntara a inculcar los sentidos de responsabilidad, esfuerzo y auto-aprendizaje en la población y los anhelos de progreso material y moral que se debatían en esos años, bajo la noción genérica de "crisis moral" por parte de los ensayistas nacionales del centenario.

Latcham se hizo cargo del "estado de la cuestión", tanto del saber antropológico que existía en el país como del conocimiento empírico de los pueblos indígenas que no habían sido estudiados. De esta manera, contribuyó de manera empírica a acrecentar los análisis craneométricos de las sociedades indígenas del pasado, en su dimensión de arqueólogo desenterró antiguos restos óseos de cementerios prehispánicos, comparándolos con las comunidades actuales. Una perspectiva que las corrientes francesas e inglesas de la antropología física consideraban importante para el mapa de la paleontología humana.

Estas investigaciones in situ le proveyeron de las evidencias científicas para diferenciar las distintas poblaciones y culturas indígenas chilenas y hacer visible el conocimiento sobre la cultura atacameña del desierto de Atacama y de las poblaciones de changos en la costa norte del país. Sin duda, que las relaciones y los estudios llevados a cabo por el arqueólogo alemán Max Uhle le abrieron el horizonte de los múltiples nexos entre las poblaciones indígenas transfronterizas de Argentina, 


\section{José Antonio González}

Bolivia, Perú, etc., y las asentadas en el territorio nacional. En este contexto, Latcham nos legó un modo de hacer arqueología, de modo científico, con un agudo espíritu de observación, de comparaciones analíticas entre yacimientos arqueológicos, registros de campos, lectura de autores vigentes en los campos que exploró y, a su vez, la capacidad de rectificar en el plano de las ideas, provisto de las pruebas imprescindibles para ello, erróneas teorías, que, a su juicio, contribuían a entorpecer el avance de la ciencias sociales en los planos de la educación - los manuales de historia prehispana- y de la cultura en general. Una de sus herencias fue la rectificación del mapa étnico de Chile. Desplazó el conocimiento de los pueblos indígenas hacia el desierto de Atacama - y con ello la frontera étnica - poniendo de relieve la avanzada cultura del pueblo atacameño.

La nueva realidad prehispánica quedó incorporada en los manuales de historia. Su lección también abordó la incorporación crítica de las viejas crónicas coloniales al saber de los pueblos indígenas. Aquello podía iluminar pistas de costumbres y mentalidades que el cientista debía corroborar en un trabajo etnográfico, como fue su experiencia entre los araucanos, o bien explorar los sitios geográficos en busca de evidencias arqueológicas o monumentales, como lo demostró en su periplo en la precordillera de Antofagasta con la constatación de las fortalezas del pueblo atacameño, o en sus excavaciones en diversos conchales y cementerios del litoral.

En definitiva, Latcham aportó a nuestra cultura la persistencia de un programa de investigación arqueológica no desvinculada de otras etnias latinoamericanas, que se vio proyectada en su acción museográfica, destacando las contribuciones dispares de los pueblos originarios, base étnica del pueblo chileno.

Universidad Católica del Norte* Facultad de Ciencias Jurídicas Casilla 1280, Antofagasta (Chile) jagonzal@ucn.cl

\section{OBRAS CITADAS}

Alegría Licuime, Luis. "Museos y Campo Cultural: Patrimonio indígena en el Museo de Etnología y Antropología de Chile", en Revista Conserva 8 (2004):57-70.

------- "Las colecciones del Museo Histórico Nacional de Chile: ¿"Invención” o "construcción" patrimonial?, Anales del Museo de América 15 (2007):237-248. 
Barros Arana, Diego. Historia General de Chile. Centro de Investigaciones Diego Barros Arana. Santiago de Chile: Tomo I. Editorial Universitaria, 2000.

Breton, A. C. "Reviews. Archaeology in Chile.Uhle", Man 19, Royal Anthropological Institute of Great Britain and Ireland, (1919):140-143.

Feliú Cruz, Guillermo. Ricardo E. Latcham (1869-1943). La bibliografia de las ciencias antropológicas. Bibliógrafos chilenos. Santiago de Chile, 1969.

Fuenzalida, Humberto. "Don Ricardo Latcham", en Revista Chilena de Historia y Geografía 104 (1944):51-101.

------ "Homenaje a don Ricardo E. Latcham 1868-1943", Publicación ocasional 5, Museo Nacional de Historia Natural (1964).

González Pizarro, José Antonio. "La literatura de ensayo y las imágenes nacionales de Chile y Bolivia a comienzos del siglo XX", Universum 24 Vol.1 (2009):82-109.

------ "Patrimonio, museos y arqueología. De la visibilidad de los pueblos indígenas a la institucionalización de los estudios arqueológicos en el Norte Grande de Chile", en Revista Diálogo Andino 36 (2010):15-32.

Gundermann, H. y González, H., "Sujetos sociales andinos, antropología y antropólogos en Chile", Revista Alpha 29 (2009):105-122.

Keller, Carlos, "Introducción" Los aborígenes de Chile, Ed. Fondo Histórico y Bibliográfico José Toribio Medina, Santiago de Chile, 1952.

Latcham, R. E., "Notes on Chilian Anthropology", The Journal of the Royal Anthropological Institute of Great Britain and Ireland 33, (1903):167-178.

------ "Notes on the Physical Characteristics of the Araucanos", The Journal of the Royal Anthropological Institute of Great Britain and Ireland 34 (1904):178-180.

------ "Notes on Some Ancient Chilian Skulls, and Other Remains", The Journal of the Royal Anthropological Institute of Great Britain and Ireland 34 (1904a):234-254.

------ “Hasta dónde alcanzó el dominio efectivo de los Incas en Chile?”, Revista Chilena de Historia Natural 4 (1908):178-199.

------ Los changos de las costas de Chile. Imprenta Cervantes, Santiago de Chile, 1910.

------ "Los elementos indígenas de la raza chilena", en Revista Chilena de Historia y Geografia 8 (1912):303-329.

------ Conferencias sobre Antropología, Etnología y Arqueología. Parte I. Lo que son estas ciencias, Imprenta Universitaria, Santiago de Chile, 1915.

------ "Los aborígenes de Chile por José Toribio Medina. Su valor científico en la actualidad", Revista Chilena de Historia y Geografia tomo XLV (1924):302-307.

------ Organización social y creencias religiosas de los antiguos araucanos, Imprenta Cervantes, Santiago de Chile, 1924a. 
------- "El problema de los orígenes de los araucanos", Revista Universitaria Universidad Católica 8 (1927):1116-1129.

------ "Tubo para aspirar rapé, con decoración Centro-americana", Revista Chilena de Historia Natural 31 (1927a):252-255.

------ "Las influencias Chinchas en la antigua alfarería chilena", Revista Chilena de Historia Natural 31 (1927b):186-192.

------- "Las influencias de la cultura de Tiahuanaco en la antigua alfarería", Revista Chilena de Historia Natural 3 (1927c):220-237.

------ "La alfarería de los antiguos atacameños", Revista Universitaria Universidad Católica 5 (1927d):560-580.

------- "La alfarería negra de la región atacameña", Revista Chilena de Historia y Geografia 8 (1927e):1060-1076.

------- "Chile Prehispano. El problema de los araucanos", Revista Chilena de Historia y Geografia tomo LVII (1928):44-91.

------ La alfarería indigena chilena, Sociedad Imprenta y Litografía Universo, Santiago de Chile, 1928a.

------- Prehistoria de Chile, Oficina del Libro, Santiago de Chile, 1928b.

------ Los Incas. Sus orígenes y sus ayllus, Establecimientos Gráficos Balcells, Santiago de Chile, 1928c.

------ Las creencias religiosas de los antiguos peruanos. Establecimientos Gráficos Balcells \& Co., Santiago de Chile, 1929.

"Los indios de la cordillera y la pampa en el siglo XVI", Revista Chilena de Historia y Geografía 67 (1930):136-172.

"Memoria del Director del Museo de Historia Natural, año 1935", Boletín del Museo de Historia Natural Tomo XV (1936): 187-191.

"Ruinas preincaicas en el norte de Chile", Boletín del Museo de Historia Natural Tomo XV (1936):21-34.

"Indian Ruins in Northern Chile", American Anthropologist New Series 1 vol. 38, (1935a):52-58.

------ "Atacameño Archaeology", American Anthropologist New Series 4 vol.38 (1936b):609-619.

"Memoria del Director del Museo de Historia Natural, año 1936", Boletín del Museo de Historia Natural Tomo XV (1936c):193-194.

------- La agricultura precolombina en Chile y los países vecinos, Ediciones de la Universidad de Chile, 1936d.

------ "Memoria del Director del Museo de Historia Natural, año 1937", Boletín del Museo de Historia Natural Tomo XVI (1937):143-149.

------- Arqueología de la Región Atacameña, Prensas de la Universidad de Chile, 1938.

------ “Tejidos atacameños”, en Revista Chilena de Historia Natural vol. 43 (1939):62-68. 
------ “Algunos tejidos atacameños", en Revista Chilena de Historia Natural vol. 44 (1940):7-11.

------ "Antropogeografía prehistórica del Norte de Chile”, Boletín del Museo Nacional de Historia Natural vol.20 (1942):5-17.

Laval, Ramón A. "Primera parte. Diccionario de Autores y Obras (Biobibliografía y bibliografía) por Emilio Vaïsse, precedido de una Bibliografía de Bibliografías Chilenas por Ramón A. Laval”, Bibliografia General de Chile. Imprenta Universitaria, Santiago de Chile, Tomo I, 1915.

Le Paige, P. Gustavo, "Ricardo Latcham y el cementerio indígena de Tchecar (S. Pedro de Atacama)", Boletín del Museo de Historia Natural, Tomo XXX (1968-1969):89-94.

Lothrop, S.K, "Richard E. Latcham 1869-1943”, American Anthropologist New Series 4 Vol.47, (1945):603-606.

Mostny, Grete, Epistolario de Augusto Capdeville con Max Uhle y otros arqueólogos e historiadores. Fondo Histórico y Bibliográfico José Toribio Medina, Santiago de Chile, 1964.

"Ricardo E. Latcham, su vida y su obra", Boletín del Museo Nacional de Historia Natural tomo XXX, Santiago de Chile (1967):9-32.

------ "Biobibliografía Museo Nacional de Historia Natural 1830-1980". Ministerio de Educación Pública. Dirección de Bibliotecas, Archivos y Museos. Museo Nacional de Historia Natural, Santiago de Chile. 1980.

Núñez Henríquez, Patricio, "Augusto Henri Capdeville Rojas: Tópicos de Chile y su época”, Taltalia. Revista del Museo Augusto Capdeville R. de Taltal 1 (2008):11-20.

Nuñez, Lautaro, "History of Archaeology in Chile", Enciclopedia of Archaeology. History and Discoveries. Edited by Tim Murray, ABC CLIO, Santa Bárbara, California, Volume I, A-D, 301-315. 2001.

------ "La investigación de Friedrich Max Uhle en el desierto de Atacama (norte de Chile)", en Max Uhle (1856-1944). Evaluaciones de sus investigaciones y obra. Ed. P.Kaulicka, M. Fisher, P.Masson y G.Wolff. Fondo Editorial de la Pontificia Universidad Católica del Perú, (2010):337-348.

Orellana Rodríguez, Mario, Historia de la Arqueología en Chile, Colección Ciencias Sociales Universidad de Chile, Bravo y Allende Editores, Santiago de Chile, 1996.

Introducción a la Antropología, Ediciones de la Universidad Internacional SEK-Corporación de Promoción Universitaria, Santiago de Chile, 2001.

Parentini, Luis Carlos, Introducción a la etnohistoria mapuche, Dibam- Centro de Investigaciones Diego Barros Arana, Santiago de Chile, 1996. 
Pinto Rodríguez, Jorge, La formación del Estado y la nación, y el pueblo mapuche. De la inclusión a la exclusión, Dibam-Centro de Investigaciones Diego Barros Arana, Santiago de Chile, 2003.

Porter, Carlos, "Bibliografía Chilena de Antropología y Etnología. Trabajo presentado al $4^{\circ}$ Congreso Científico ( $1^{\circ}$ Pan-Americano)", Anales del Museo Nacional de Buenos Aires tomo XX, (1910):147-148. Con un prólogo de Ricardo E. Latcham, miembro correspondiente del "Royal Anthropological Institute of Great Britain and Ireland". Edición del autor, Imprenta "Juan A. Alsina", Buenos Aires, calle México 1422.

Smith, Edmond R. Los Araucanos o Notas sobre una gira efectuada entre las tribus indigenas de Chile Meridional. Traducción de Ricardo E. Latcham, de la Sociedad Chilena de Historia y Geografía. Colección de Autores Extranjeros, relativos a Chile; publicada bajo la dirección de la Sociedad Chilena de Historia y Geografía. Segunda Serie, Tomo I. Imprenta Universitaria, Santiago de Chile, 1914. 